From scarcity to abundance - organisational sustainability and the role of the civic entrepreneur

\author{
Sam Wells \\ Adelaide Graduate School of Business
}

Email: sam.wells@adelaide.edu.au

Stream: $\quad$ F. Sustainable Enterprise 


\title{
From scarcity to abundance - organisational sustainability and the role of the civic entrepreneur
}

\begin{abstract}
:
This paper examines the implications of the enormous scope of 'sustainability' literature, which reflects the fragmentation of sustainability knowledge - the product of a reductionist tradition. The paper sketches some of the conceptual challenges that need to be addressed if the pursuit of sustainability is to take the important step from fragmentation and 'scarcity', to integration and 'abundance'.

Perhaps the most productive response to the sustainability challenge is not to react to each individual problem, at the level of the problem. Perhaps we need now to conceive a higher level of synthesis - an appreciation of the interconnectedness of components in the 'complex system' of human ecology.

In particular, the paper explores the important role of commercial enterprise, which is naturally integrative, in grappling with some of these critical issues. It proposes a special role for the "civic entrepreneur' in helping larger organisations to take the next big step towards practical sustainability by piloting new models of proactive integration and abundance.
\end{abstract}

"We've made tremendous progress in science for 300 years, since the days of Isaac Newton and the scientific revolution by chopping problems up into smaller and smaller bits and analysing the tiniest parts ... but the time has come to move back up. I mean how [do] we understand the behaviour of a whole economy? How do we understand the resilience and stability of ecosystems? Or global warming? These are problems with a similar character in that you can't understand them by looking at the little bits. And this is a daunting challenge going up turns out to be much harder than going down. Synthesis and holism is much more scientifically subtle than analysis and reductionism.”

Steve Strogatz, Professor of Applied Mathematics, Cornell University ${ }^{1}$

\section{FRAGMENTATION OF SUSTAINABILITY KNOWLEDGE}

The notion of sustainability, as the term has come to be used over the last 15 years or so,

reflects a very wide range of interests and aspirations. They all have their origins in a general awareness that the 'ecology' of human existence on earth is not healthy. Past that shared 
awareness, however, it is difficult to identify a single thread that runs through the myriad studies exploring the problems and solutions associated with the ecological dilemma, or that brings to them a sense of disciplinary (or inter-disciplinary) integrity and unity of purpose.

It was in the nature of the dilemma that every facet of human ecology should come to be considered a legitimate field of study, under the banner of sustainability. The result was an explosion of knowledge, a huge amount of work undertaken on relatively narrow fronts by social and physical scientists, academics in all disciplines, consultants, practitioners - explosive not only in its speed and scope, but also in its fragmentation. ${ }^{2}$ These discreet packets of new expertise and understanding came to be seen as 'add-ons' to various spheres of human activity, ways of addressing some particular manifestation of the sustainability challenge. It has been an essentially reactive process - we are making a mess of this or that activity, so what are the things that we should stop doing or do differently?

Nowhere has this been more apparent than in regard to corporations. The early 'sustainability' focus on corporations was prompted by a perception that they were, wittingly or unwittingly, doing harm that needed to be put right. ${ }^{3}$ They were seen by some, not as potential vehicles for beneficial change, or potential models of a new human ecology, so much as errant institutions whose ways needed to be mended by the piecemeal application of new knowledge to this or that activity. Indeed the opportunity to reconceive the organisation as a model of sustainable living for human communities, was constrained by the very language of sustainability.

\section{POWER OF LANGUAGE TO CONSTRAIN THINKING}

Language is powerful, for good and ill. It could be argued that the 'triple bottom line', the rallying call of so many who seek a different measure of corporate success, is self-limiting. How can we achieve the integration demanded by the complexity of human ecology, when we must 
measure corporate performance in three separated spheres of activity, and develop three measures of value, three 'currencies', or submit to one currency that cannot do justice to the whole? ${ }^{4}$

The notion of 'sustainability' itself has become associated, by virtue of the reactive nature of the thinking and work done under its banner, with a sense of maintaining an acceptable status quo, preventing any decline, preserving what we have. It tends to reflect and cement a paradigm of 'scarcity, ${ }^{5}$ in which we are always trying to hold the line, prevent entropy, corral, protect, conserve, make the most of what's left. It reinforces a sense of limited integration.

What are we trying to sustain? Is it a world in which biodiversity neither decreases nor increases; in which the measure of social health is no more than an absence of social disease; in which economic fairness means dividing existing resources fairly, without any opportunity to grow new wealth (cf. Korhonen, 2004, p.810)? Perhaps the next major step towards practical sustainability will involve "going up" to a new level of synthesis and integration that cannot be achieved simply by adding the numerous, but fragmented, pieces of expert knowledge together.

\section{STICKS \& CARROTS UNDERMINE INTRINSIC MOTIVATION \& CREATIVITY}

In what follows, these issues of synthesis and integration will be explored as they apply to the practical study of organisations and enterprise. A clear distinction should be made between two branches of that study: a) what businesses should do, and b) what businesses could do. Our concern is with the latter only, and the distinction is very important.

A great deal has been written about the obligations - legal and moral - on corporations to behave in a particular way, and about the best way of ensuring that they meet those obligations. One can sympathise with those who seek to prevent the damage caused by corporate neglect or vandalism, but a glance at what we know about individual motivation confirms that debate about regulation or obligation is not a sound basis for the next major step towards sustainability. Kohn's (1993) 
landmark article on incentives spelled out what so much research before and since has established: Sticks and carrots, punishment and rewards, are all manipulative - two sides of the same coin. In particular, these so-called "extrinsic motivators", while perhaps achieving temporary and superficial compliance, actually undermine the foundations of longer-term, sustainable behaviour - they undermine intrinsic motivation and creativity in individuals. The same can confidently be predicted of organisations.

The important questions are not about whether organisations can be induced to 'do the right thing', but about what the right thing looks like and how it can best be pursued by those who want to pursue it. In other words, the next big step towards organisational sustainability is only likely to be conceived and achieved by those who seek it - you cannot legislate for innovation and enterprise.

\section{ROLE OF "CORPORATIONS"}

"You can never solve a problem on the level on which it was created." Albert Einstein captures the sustainability challenge for organisations. The solutions lie in a higher level of synthesis, which extracts order from apparent chaos and simplicity from apparent complexity.

Students of corporate sustainability, who seek insights into a more integrated vision of possibilities for the world of organisation, have reason to be grateful - and to express gratitude for the work of Dexter Dunphy and his colleagues (Dunphy et al. 2003). Here, indeed, is a willingness to think afresh and to seek solutions at a more holistic, sophisticated and subtle level than that at which the problems present (Dunphy et al. 2003, p.83). But this powerful thinking is presented as a foundation for practical action: "The time to debate abstract theories is past; what we need now is to imbed our theories in action and to engage in dialogue around working 
models." (Dunphy et al. 2003, p.4). By focusing on corporations, in pursuit of sustainability, Dunphy et al. are mindful of the power of larger corporations, for good and ill:

Corporations ...control most of the resources of our global society; if we are to have effective leadership of the sustainability movement, then much of the movement must come from the corporate sector. (Dunphy et al. 2003, p.83).

The challenge is to work out how we can put these organisations on the path to becoming "sustaining corporations", and it is logical that Dunphy and his colleagues should take the perspective of corporate 'change agents' or 'change leaders' at various levels, in various roles, inside and outside the organisation. They track the corporation through a phased evolution, from resistance, to non-responsiveness, to compliance, to sustainable efficiency, to strategic proactivity, and the change agent must develop the skills and resources to play a part in “unfolding the 'implicate order"” (Dunphy et al. 2003, p. 293). The exploration, and explication, of the 'incremental' and 'transformational' paths of change is a masterful blend of scholarship and practical wisdom.

We have highlighted this work of Dunphy et al. on corporate sustainability, for three reasons. First, it stands out from the sustainability literature as a particularly insightful and bold (and compelling) conception of the sustaining organisation and its cultivation. Second, it starts to establish the case for a special role for commercial enterprise, in the broadest sense of the word, in leading the modelling of sustainability - this is a theme we will build on further.

Finally, in the context of organisational change, Dunphy et al. touch on one particular change component - the role of the 'pilot'- that should be explored further if we are to do justice to the value of enterprise, in particular entrepreneurial enterprise, in underpinning the pursuit of sustainability. We make bold here to propose an extension of the thinking reflected in Dunphy et 
al., as a "dwarf standing on the shoulders of a giant" - perhaps it may still be possible to see a little further. ${ }^{6}$

\section{SPECIAL CONTRIBUTION OF COMMERCIAL ENTERPRISE}

Large corporations certainly do have substantial resources that can be brought to bear on the complex challenges of sustainability, as Dunphy et al. suggest. But commercial enterprises of all shapes and sizes exhibit other qualities that enable them to make a special contribution.

I have characterised the central challenge in taking the next step towards sustainability as achieving a new level of synthesis or integration. Enterprise is naturally integrative. Enterprises act as 'open systems' (Katz and Kahn, 1969), pulling together a vast array of interconnected and interdependent components, in order to create wealth. The best of them manage to "balance everything" - "It's not a case of A or B but A and B...and C and D and so on" (Hubbard et al., 2002, p. 266). There is an unwillingness to compromise, to seek the lowest common denominator -

...a highly visionary company doesn't want to blend the yin and yang into a gray, indistinguishable circle...it aims to be distinctly yin and distinctly yang - both at the same time, all the time (Collins and Porras, 1994, pp.44-5)

When we begin to explore notions of 'wealth' that reflect not just a triple bottom line but also, one might suggest, a 'triple balance sheet', and to question the assumption that shareholders are the only stakeholders whose interests can legitimately be reflected in the activities of the corporation (e.g. Handy, 2002), then this genius for integration in the best enterprises emerges as an important consideration in modelling sustainability.

Corporations can be thought of as communities in their own right (Handy 1997, pp.179-204). As such they can become practical models of sustainable living, not just for other organisations, but also for the wider communities in which they operate and, indeed, for 'the community' generally. Their special capacity for integration and wealth creation can be directed to the creation of 
sustainable "common wealth". Hart and Milstein (2003) begin to explore the possibilities presented by this capacity for value creation. Hart and Christensen (2002) make the connection even more powerfully in the special case of enterprise operating at the "base of the pyramid" in the poorest communities - an example to which we will return.

So corporations have an important role to play in building a sustainable world, not just because they are resource rich and powerful, but also because, as enterprises, they are naturally integrative and have the capacity to establish themselves as models of sustainable community. In order to bring their capacity for integration and wealth creation to the service of sustainability, established businesses must travel the path of organisational change mapped out by Dunphy et al. But change leaders are dealing with the entrenched values and assumptions of corporate cultures and corporate 'orthodoxies' - that are extraordinarily resilient, and resistant to managed, incremental change, let alone to a paradigm shift. It is difficult for change makers even to conceive the way forward themselves, let alone to carry their unwieldy organisations with them down the path to a new vision of sustainability - it's like wading through molasses. ${ }^{7}$

\section{VALUE OF 'PILOTS' IN FACILITATING CHANGE}

Dunphy et al. (2003, pp.229-30) recommend piloting new practices and innovations. They see this as a means of testing and refining, "rather like debugging a software program before its widespread adoption". Pilot programmes also allow us to "test the appropriateness of the tools, and redesign techniques and forms of participation...".

We would propose that pilots have a value beyond that signalled by Dunphy et al. - that their value is often as great to change followers as it is to change leaders.

Change leaders often become frustrated. Although the need for change, and what things will look like after the change, is very clear to them, it often happens that many of the potential followers 
somehow do not 'get it', no matter how often or passionately the word picture is painted for them. Our experience suggests that a large part of this gap between change leader and follower can be attributed to differences in conceptual thinking capability. ${ }^{8}$

Conceptual thinking involves the ability to recognise patterns, to identify the order underlying apparent chaos, to think beyond linear analysis to a point that can only be reached by a conceptual 'leap' but that, once reached, seems logical in hindsight. ${ }^{9}$ Change leaders can 'see' the great merits in moving from organisational state A to state B, and they can happily make that journey - the conceptual leap - in their head. Many of their followers, whose thinking is shaped by the more prevalent analytical mode, will struggle to make sense of the conceptual journey to state B - that is, they will struggle to make the journey in their head. The end of the journey, which the leader espouses in such passionate terms, can only be real to them if they can touch and taste and hear and see and smell it. Once they have had that concrete experience of state B, they can look back to state A and make sense of the journey in retrospect. This is not a matter of good or bad thinking or more or less intelligence, but a different mode of thinking - a difference that must be recognised by the change leader.

Enter the pilot programme. Assuming it is well designed and conducted (and correctly conceived!), the pilot gives concrete experience of the end point to a group of change followers. It allows them to make sense of the journey in retrospect and to embrace its merits. Furthermore, the journey they have travelled and their approval of its destination have been witnessed, and experienced vicariously, by their peers. The conceptual leap becomes a logical step.

The same principles that underpin this value of pilots within established organisations have application in the commercial community at large. The resilience of corporate 'orthodoxy' and the entrenched values and assumptions that shape the culture of well-established corporations 
make it difficult to lead organisational change. Dunphy et al. provide a tool kit for internal and external change agents, operating within the cultural and conceptual constraints of a particular corporation. But there is a special kind of 'enterprise piloting', operating outside the world of large corporates, that can give concrete expression to new, integrated models of sustainable enterprise, and provide strategic change leaders with a 'library' of practical examples that can help their 'followers' (which may include the Senior Executive Committee, or the Board of Directors) to make sense of the change journey.

\section{THE CIVIC ENTREPRENEUR IN ACTION}

Entrepreneurs are wealth seekers and wealth creators. They see the 'big picture' and do not recognise any firm boundaries between their personal enterprises and the rest of the 'system'. They understand, value and leverage the interdependence and interconnectedness of the system components. They are creators and innovators. Above all they have an abundance mentality. Their ability to integrate, to make the connections between things that other people have not connected, impel them to embrace the "genius of the AND" (Collins and Porras, p.44). They refuse to be constrained in their thinking and action by fighting for 'their share' of a finite cake their recipe has more in common with Norman Lindsay's "Magic Pudding" (1918), which regenerates as it is consumed and can be whatever kind of pudding the owner desires, slice by slice.

Civic Entrepreneurs bring all these qualities to the table, but the pursuit of personal wealth is complemented by the desire to create sustainable 'common wealth' with and for the community in which they operate. ${ }^{10}$ They do not seek to plunder one component of the system, but look to understand, nourish and elevate the performance of the whole system. Enterprise is not seen as a vehicle for extracting wealth from the community, but for generating new capital to underpin new community enterprise and wealth. Environmental and social 'wealth' are not add-ons, but are 
indistinguishable from economic wealth - integration extends across 'currencies'. The collaboration required between businesses, government (especially local government), educators, non-government agencies, and community groups and members in order to support this level of integration is cultivated by the civic entrepreneur's abundance mentality. There is no need to protect the 'turf', or the profile, or the commercial interests, or the special mission of this or that collaborative partner. There is enough for everyone - enough independence, kudos, profit, fulfilment. More than enough, an abundance... because the system has no boundaries.

Civic entrepreneurs have an eye out for the 'little guy' - they understand the special opportunities that exist when operating at the 'base of the pyramid' (Hart and Christensen, 2002; "Bridging the Gap: Sustainable Environment", 2004). The following sketch of civic entrepreneurship in action draws on a project currently being designed, in conjunction with local government and community stakeholders. The project aims to provide a suburban community, oppressed by decades of economic, social and environmental neglect, with the opportunity to reinvent and reinvigorate itself by creating common wealth at all levels. ${ }^{11}$

The civic entrepreneur operates on two fundamental principles. First, that the generation of common wealth must be undertaken by a community, not for it. Second, that the economic, social and environmental benefits created by civic entrepreneurism only become 'real' when they are imbedded in the community - when the community itself becomes both the vehicle and the guardian of common wealth (this demands what we might call a 'quadruple bottom line': economic benefit, social benefit, environmental benefit and sustainable community - cf. Stead et al., especially p.64).

2000 new homes to replace the dilapidated and depressing rental housing are built in partnership between the builder/developer and the community's central economic vehicle - perhaps a limited liability company that encourages individual and corporate investment, but is controlled by the 
community. The new homes are simply and inexpensively constructed. They are also beautiful (not ornate) and make a positive ecological contribution - for example, whenever the solar or wind energy they generate collectively is greater than net consumption, the excess is sold back to the grid. The development is designed to reinforce the health of the community - support for extended family, integration of living, working and playing, and the breaking down of boundaries between 'living' space and agricultural/horticultural enterprise. (The latter can be safely achieved on the basis of commitment to the booming organic produce market, which eliminates the residential dangers of chemical 'overspray'.)

The buying power generated by such a large building volume secures a financing deal that ensures that mortgage payments are no greater than public housing rents. Finance may be provided by the new community bank, or a community joint venture with an existing bank or credit union.

The principle builder in this project is bound by a non-negotiable proviso - apart from expert building and trades supervisors, the houses are built by their new owners, employed by the builder under 'Traineeships', in collaboration with the local colleges for vocational education. So these members of the community acquire new homes, employment during the duration of the housing project, new skills to support subsequent employment or self-employment and, most importantly, a sense of 'ownership' that goes well beyond the finance package.

So many new homes require a lot of new trees to be planted. Sufficiently numerous, in fact, to support the creation of a community nursery, owned partly by the community investment company (CIC) and partly by its new managers. This business has the additional task of supplying trees for the new golf course (funded by corporate investment, the CIC and individual community members, who have access to very affordable 'units' of ownership). Each hole in the 
golf course is designed and, eventually, built by its own group of local citizens, acting under the training and guidance of a professional golf course developer - they may not be let loose on the most expensive front-end loader, but they pick up lots of other skills in design, project management and landscaping along the way.

Golf courses require a great deal of water. This one is watered by the community's collective stormwater, gathered in an elongated 'lake', filtered of excess nutrients and other pollutants through extensive reed beds, stored in underground aquifers and recovered as required for the golf course and other green spaces. The lake becomes a practice space for rowing crews from the local high schools. Historically it would have been laughable for them even to contemplate competing against the private colleges - in the hands of the civic entrepreneur, nothing is unimaginable, no symbol of abundant community is beyond reach.

And so the endless fabric of interconnections and leveraged integration is woven. Every need is an opportunity for collaborative enterprise. Every new enterprise is a springboard for generating more common wealth. The spiralling sense of abundance brings the conceptual insight and creativity of the entrepreneur to the service of sustainable community.

\section{PILOTING SUSTAINABILITY FOR CORPORATIONS}

The work of civic entrepreneurs in creating sustainable community can act as 'piloting' for larger organisations, where change leaders are looking for conceptual models and concrete expressions of a new level of synthesis and integration.

If large corporations, with all the resources at their disposal, are to take the next step towards sustainability - a step flagged by the new science of networks and complex systems - they must provide their change followers, at all levels, with living demonstrations, and the vicarious experience, of sustainable community. Models of proactive 'abundance' must be made clearly 
visible as alternatives to the paradigm of reactive 'scarcity' that shapes our current views of organisational sustainability - models that can be drawn upon by corporate change leaders, as they seek to establish new forms of sustainable corporate community, within community.

This is the world of the civic entrepreneur. Such individuals are a rare and precious resource.

Their thinking and their work should be leveraged by corporate change agents - the civic entrepreneurs would certainly approve. 


\section{References}

'Bridging the Gap: Sustainable Environment', UN Global Compact Academic Conference, Summary of proceedings, September, 2004. Retrieved $7^{\text {th }}$ January 2005 from http://www.wharton.universia.net/index.cfm?fa =viewArticle\&id=888\&language=english \&specialId $=79$

Banuri, T and Najam, A (2002) Civic Entrepreneurship - A Civil Society Perspective on Sustainable Development. Volume 1: Global Synthesis, Gandhara Academy Press, Islamabad.

Buchanan, DA, Ketley, D, Gollop, R, Jones, JL, Lamont, SS, Neath, A and Whitby, E (2003) 'No going back: a review of the literature on sustaining organisational change', NHS Modernisation Agency, Research into Practice Report No. 7, November

Collins, J and Porras J (1994) Built to Last: Successful Habits of Visionary Companies,

Dunphy, D, Griffiths, A and Benn, S (2003) Organizational Change for Corporate Sustainability: A guide for leaders and change agents of the future, Routledge, London and New York.

Greenleaf, R C (1983) Servant Leadership, Paulist Press, Mahwah.

Handy, C (1997) The Hungry Spirit, Hutchinson, London.

Handy, C (2002) 'What's a Business For?', Harvard Business Review, December, pp.49-55.

Hart, SL and Christensen, C (2002) 'The great leap: driving innovation from the base of the pyramid', Sloan Management Review, 44, pp.51-56.

Hart, SL (1997) 'Beyond Greening: Strategies for a Sustainable World', Harvard Business Review, January-February, pp.66-76. 
Hart, SL and Milstein, MB (2003) 'Creating Sustainable Value', Academy of Management Executive, Vol. 17, pp.56-67.

Henton, D, Melville, JG and Walesh, K (1997) Grassroots Leaders for a New Economy: How Civic Entrepreneurs Are Building Prosperous Communities, Jossey-Bass, San Francisco. Hubbard, G, Samuel, D, Heap, S and Cocks, G (2002) The First XI: Winning Organisations in Australia, John Wiley \& Sons, Milton.

Katz, D and Kahn, RL (1969) 'Common Characteristics of Open Systems', in Systems Thinking, (ed. Emery, FE) Penguin Modern Management Readings, New York.

Kohn, A (1993) 'Why Incentive Plans Cannot Work', Harvard Business Review, SeptemberOctober, pp.54-63.

Korhonen, J (2004) 'Industrial ecology in the strategic sustainable development model: strategic applications of industrial ecology', Journal of Cleaner Production, Vol.12, pp.809-823.

Lindsay, N (1918) The magic pudding: being the adventures of Bunyip Bluegum and his friends Bill Barnacle and Sam Sawnoff, Angus \& Robertson, Sydney.

Newton, T and Harte, G (1997) 'Green business: Technicist kitsch?', Journal of Management Studies, Vol. 34, pp.75-98.

Spencer, L M and Spencer, SM (1993) Competence at Work: Models for Superior Performance, Wiley, USA.

Stead, W. E., Stead, J. G. and Shemwell, D. J. (2002) 'Community sustainability comes to the Southern Appalachian region of the USA: the case of Johnson County, Tennessee', in Research in Corporate Sustainability (ed. Sharma, S. S., Mark) Edward Elgar Publishing, Cheltenham, UK; Northampton, USA, pp. 61-84. 


\section{Notes}

${ }^{1}$ On The Science Show, "The New Science of Networks", written and produced by Annamaria Talas and presented by Simon Nasht, Saturday 8 January 2005 on ABC radio.

${ }^{2}$ I acknowledge here the research assistance of Julia Inverarity in grappling with the literature of Sustainability.

3 Dunphy et al., 2003, pp.8-10, summarise the history.

${ }^{4}$ Cf. the view expressed by Paul Tebo, Vice President for Safety, Health and the Environment, E.I. du Pont de Nemours: "I fully expect that we'll no longer be talking about economic, environmental and societal values as being distinctly different, but see them as integral and interlocking aspects of every business process and activity" (cited in Dunphy et al. (2003), p.83).

${ }^{5}$ Stephen Covey (1990) The 7 Habits of Highly Effective People, Simon and Schuster, New York, pp.119-120, coined "abundance mentality" and "scarcity mentality" in relation to individuals and how they approach their relationships. The principles have much wider application wherever complex systems are in play - an abundance mentality is the basis of synergistic thinking and creative interdependence.

${ }^{6}$ In the early $12^{\text {th }}$ Century, the Chancellor of the Cathedral School of Chartres, Bernard of Chartres, said that compared to the newly re-discovered classical authors the contemporary scholar was "like a dwarf, standing on the shoulders of a giant". The best account is in R.W. Southern (1975, first published 1953) The Making of the Middle Ages, Hutchinson, London, p.194.

${ }^{7}$ Buchanan et al. (2003) draw on the organisational change literature to canvass the complexities of organisational change and the challenges of sustaining it. Dunphy et al. (2003, p. 208) endorse Beer and Nohria ('Cracking the code of change', Harvard Business Review, 2000, July-August, p. 133): “The brutal fact is that about $70 \%$ of all change initiatives fail". Business Scotland Network (http://www.cbs-network.org.uk/).

${ }^{8}$ Spencer and Spencer (1993) provide an excellent framework for understanding the nature and organisational applications of conceptual thinking capability. Greenleaf (1983, p.66) contrasts "conceptual" and "operational" talent "Leadership, in the sense of going out ahead to show the way, is more conceptual than operating".

${ }^{9}$ Edward de Bono has made famous the ant on a tree leaf: The chances of the ant climbing from earth up the trunk to that particular leaf may be one in ten thousand - from the starting point on the trunk, it requires a conceptual or creative leap to 'see' the ant on that leaf. But once on that leaf, the chances of the ant coming back to earth via the trunk are 1:1 - it's the same pathway, but logical in hindsight.

${ }^{10}$ There are several different perspectives on civic entrepreneurship in the literature. Henton (1997) and Banuri and Ajam (2002) are representative. The emphasis in this paper is on the conceptual capability of the civic entrepreneur, but the profile is consistent with the general picture that emerges from the literature.

${ }^{11}$ I owe much of what follows to the vision and generosity of Steve Thomas, civic entrepreneur par excellence. Working with Steve is an adventure in abundance! Various elements in this model are echoed in the explosion of work on community development, worldwide. The following institutions are representative - the key for the civic entrepreneur, of course, is in the breadth and depth of integration: Sustainable Communities Network (http://www.sustainable.org/economy/commecon.html); Tompkins Institute for Human Values and Technology (http://www.ced.ca/index.html); Institute for Community Economics (http://www.iceclt.org); Community Business Scotland Network (http://www.cbs-network.org.uk/). 